\title{
Density drives polyandry and relatedness influences paternal success in the Pacific gooseneck barnacle, Pollicipes elegans
}

Louis V Plough ${ }^{1 *}$, Amy Moran $^{2}$ and Peter Marko ${ }^{2}$

\begin{abstract}
Background: Polyandry is a common mating strategy in animals, increasing female fitness through direct (material) and indirect (genetic) benefits. Most theories about the benefits of polyandry come from studies of terrestrial animals, which have relatively complex mating systems and behaviors; less is known about the potential benefits of polyandry in sessile marine animals, for which potential mates may be scarce and females have less control over pre-copulatory mate choice. Here, we used microsatellite markers to examine multiple paternity in natural aggregations of the Pacific gooseneck barnacle Pollicipes elegans, testing the effect of density on paternity and mate relatedness on male reproductive success.

Results: We found that multiple paternity was very common (79\% of broods), with up to five fathers contributing to a brood, though power was relatively low to detect more than four fathers. Density had a significant and positive linear effect on the number of fathers siring a brood, though this relationship leveled off at high numbers of fathers, which may reflect a lack of power and/or an upper limit to polyandry in this species. Significant skew in male reproductive contribution in multiply-sired broods was observed and we found a positive and significant relationship between the proportion of offspring sired and the genetic similarity between mates, suggesting that genetic compatibility may influence reproductive success in this species.

Conclusions: To our knowledge, this is the first study to show high levels of multiple paternity in a barnacle, and overall, patterns of paternity in P. elegans appear to be driven primarily by mate availability. Evidence of paternity bias for males with higher relatedness suggests some form of post-copulatory sexual selection is taking place, but more work is needed to determine whether it operates during or post-fertilization. Overall, our results suggest that while polyandry in P. elegans is driven by mate availability, it may also provide a mechanism for females to ensure fertilization by compatible gametes and increase reproductive success in this sessile species.
\end{abstract}

Keywords: Multiple paternity, Barnacles, Genetic benefits, Reproductive skew, Mating strategies

\section{Background}

Polyandry, when a female mates with more than one male in a single reproductive period, is a common mating strategy among animals [1-3]. However, explanations of mating frequency based on classical sexual selection theory (e.g. $[1,4])$ suggest that males, but generally not females, should maximize their reproductive success through numerous matings [5]. Furthermore, multiple matings can have significant fitness costs for females such as

\footnotetext{
*Correspondence: Iplough@umces.edu

${ }^{1}$ Horn Point Laboratory, University of Maryland Center for Environmental

Science, P.O. Box 775, Cambridge, MD 21601, USA

Full list of author information is available at the end of the article
}

disease contraction [6], increased predation risk [7,8], and physical injury [9-13]. Nevertheless, many field and experimental studies now show that females commonly mate multiply to acquire sperm from several males [2,3,14-19].

The solution to the apparent paradox of polyandry is that females acquire direct and indirect fitness benefits through multiple matings. Direct fitness benefits, such as increased parental care [20], protection from predators $[21,22]$, and acquisition of nutrient-rich spermatophores or seminal fluid $[8,23]$, have been described in a number of species, most notably in insects $[10,21]$. In many other taxa, however, there are no obvious direct benefits of polyandry, suggesting that females may receive indirect (or genetic) 
fitness benefits from multiple matings [2,19,24-26]. In these species, females may mate multiply to increase the likelihood of fertilization by a high quality mate through sperm competition or sperm selection $[14,15,27,28]$ (i.e. the 'good' genes hypothesis; $[18,19]$ ) or to ensure fertilization with a compatible mate (the 'compatible' genes hypothesis; [29-32]). In some cases, sperm with genotypes that differ from a particular female's eggs are more successful at fertilization or may enhance offspring viability [32-34]. In other cases, greater genetic similarity (overall, or at particular gamete recognition loci) is positively associated with fertilization success [35-37].

While polyandry has been examined extensively in behaviorally complex and mobile terrestrial animals (e.g. insects, reptiles, and birds), less considered are the conditions that affect the evolution and frequency of polyandry in sessile marine animals, most of which have resource-free mating systems [38,39], in which the benefits of polyandry are primarily indirect and mating is limited by gametic dispersal distances [40-43]. Polyandry may be beneficial (and therefore common) in sessile species if it increases the likelihood of fertilization by either high quality or genetically compatible sperm when pre-copulatory mate choice is limited $[38,41,44]$. On the other hand, polyandry may be an unavoidable consequence of reproduction in these species, its frequency a reflection of the density of conspecifics and the inability to reject or avoid multiple fertilizations. Among sessile species, barnacles are most unusual in that they copulate, such that mating is likely limited to only a handful of adjacent individuals in most species (but see [45]). Observations of social polyandry (multiple mating attempts) are common in barnacles (e.g. [46]), but genetic analyses of barnacle mating systems are limited and in some cases have yielded contrasting results with respect to the frequency of polyandry. For example, one study found that the prevalence of multiple paternity was related to density but was generally low, suggesting that siring success was mediated by the distance between mates [47], whereas an unpublished study from another non-stalked species reported polyandry in nearly $80 \%$ of broods (D.M. Rand, Cited in [47]). A third study examined paternity in broods from physically isolated individuals of the gooseneck barnacle Pollicipes polymerus, finding that some individuals had received sperm through the water column, and thus can potentially reproduce with mates outside the range of an extensible penis [45]. Finally, high relatedness and kin aggregation has been observed in Semibalanus balanoides [48] which suggests that genetic identity or compatibility may also be important in determining barnacle settlement and possibly reproductive success. Clearly, the drivers of polyandry in barnacles and other sessile marine animals are complex and more information is needed on the relative roles of ecological and genetic factors influencing the evolution of polyandry in these species.
In this study we used microsatellite markers to examine multiple paternity in a natural population of Pollicipes elegans, an hermaphroditic intertidal gooseneck barnacle that is found in high-density aggregations on rocky shores of the tropical and subtropical eastern Pacific. Based on the intriguing findings from previous studies of paternity in barnacles [46,47] and evidence of high relatedness within barnacle aggregations [48] we examined the relationship between conspecific density and multiple paternity, the effect of genetic relatedness on proportional siring success, and the extent of relatedness within P. elegans aggregations. Though it is difficult to explicitly show the genetic benefits of polyandry (e.g. $[38,39,49])$, a relationship between relatedness and siring success indicates that genetic identity is important in determining reproductive success in multiply-sired broods, potentially driving the evolution of polyandry in P. elegans.

\section{Results}

Paternity

Paternity analysis of 416 individual larvae from 14 broods and their respective mothers revealed two or more fathers in 11 of the 14 broods analyzed, with the minimum number of fathers ranging from one to five (mean of 3.36; Table 1). In six out of the 14 broods analyzed, there were multiple solutions for the reconstructed paternal genotypes (range of 3 to 427; most had fewer than 30), which were ranked by likelihood, based on Mendelian segregation. There was no effect of sample size on the number of fathers estimated (Pearson's correlation, sample size vs. number of fathers: $0.049, \mathrm{P}=0.879$ ). In the three cases of single paternity, offspring inherited at least one allele that

Table 1 Sampling densities, sample sizes and paternity results

\begin{tabular}{|c|c|c|c|}
\hline Density & Brood name & Sample size & Paternity (fathers) \\
\hline 2 & C4 & 41 & 1 \\
\hline 4 & $\mathrm{C} 1$ & 18 & 3 \\
\hline 4 & $\mathrm{C} 2$ & 22 & 1 \\
\hline \multirow[t]{3}{*}{12} & C9 & 37 & 3 \\
\hline & $\mathrm{C} 10$ & 28 & 1 \\
\hline & $\mathrm{C} 12$ & 40 & 3 \\
\hline \multirow[t]{3}{*}{17} & $\mathrm{C} 13$ & 34 & 5 \\
\hline & C15 & 28 & 4 \\
\hline & $\mathrm{C} 16$ & 22 & 4 \\
\hline \multirow[t]{3}{*}{22} & $\mathrm{C} 18$ & 31 & 4 \\
\hline & C19 & 37 & 5 \\
\hline & $\mathrm{C} 22$ & 27 & 5 \\
\hline \multirow[t]{3}{*}{44} & C3 & 21 & 3 \\
\hline & C6 & 30 & 5 \\
\hline & Average & 29.71 & 3.36 \\
\hline
\end{tabular}


was not present in the mother's genotype, demonstrating that self-fertilization was unlikely.

Our power to detect multiple paternity (two or more fathers) was very high given the markers and sample sizes available in this study. Simulations showed that the power to detect two or three fathers was relatively high (above 0.7 ) even at low sample sizes of 10 offspring, and increased to 0.97 and 0.84 (for two and three fathers, respectively) when the number of offspring was increased to the mean sample sizes from this experiment ( 30; Figure 1). However, power to detect four or five fathers was much lower; at mean sample sizes power was 0.62 and 0.32 , respectively. Skew in reproductive contribution (one father contributing only $1 / 5$ the number of offspring) also reduced power substantially in simulations of four and five fathers, but power was not substantially affected for detecting two or three fathers (Figure 1). At the average sample size from this study and the skew scenario evaluated, power to detect four and five fathers with skew was 0.42 and 0.15 , respectively.

Among aggregations for which we were able to genotype all of the adults, we found few exogenous alleles in larval broods that could have originated through spermcasting. For the two lowest densities ( 2 and 4 individuals per $10 \mathrm{~cm}^{2}$ ), densities at which we were able to genotype every individual, we found no external alleles in any larval broods. For one aggregation at a higher density (17 individuals per $10 \mathrm{~cm}^{2}$ ), for which we were able to genotype all but one adult, we found three exogenous alleles in larval broods, suggesting that at least one of these alleles originated from outside the aggregation.

\section{Effect of density on paternity}

Examining paternity in broods sampled from a range of conspecific densities (Table 1; see Methods), we found a positive and significant linear relationship between adult barnacle density and the number of contributing fathers $\left(R^{2}=0.3521, P=0.025\right.$; Figure 2). This linear relationship appeared to level off with higher density and regression of paternity on log-transformed density produced a better overall fit $\left(\mathrm{R}^{2}=0.513, \mathrm{P}=0.0041\right.$; Figure 2$)$.

\section{Reproductive skew and effect of relatedness}

Reproductive contribution of fathers in multiply sired broods was variable, differing significantly from the expectation of equality (evidence of significant reproductive skew) in four of the 11 broods analyzed (Figure 3). In the broods showing significant departures from equal paternal contributions, the patterns of skew were different. For example, in brood c13, most of the offspring (57\%) were sired by one individual, while the other four fathers sired somewhat equal (goodness-of-fit Chi-square for the four fathers, $P=0.61$ ), but far smaller numbers of offspring. In brood c12, two of the fathers sired an approximately equal proportion of the offspring (45\% each), with the 3rd father siring far less (10\%).

The permutation-based test of correlation revealed a positive and highly significant association between parental relatedness and the proportion of a given brood sired by putative fathers (Spearman's Rho $=0.38, \mathrm{P}=0.0084$; Figure 4A). This relationship was robust to a number of different relatedness estimators including that of Queller and Goodnight [50] $(\mathrm{P}=0.004$; Figure 4B). Overall,

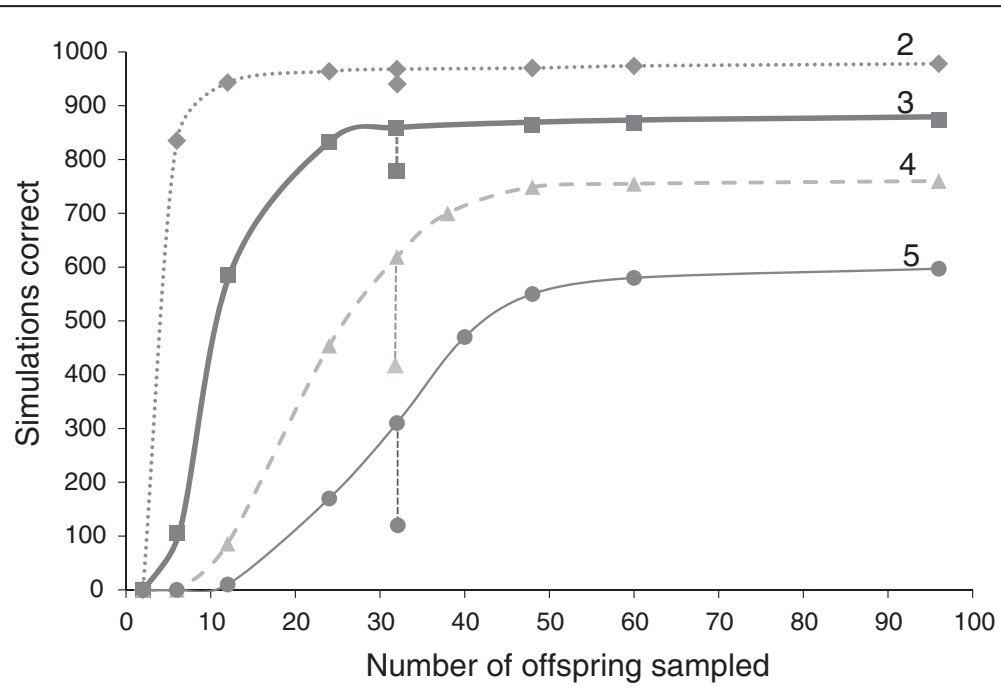

Figure 1 Power simulation results for detecting multiple paternity with various numbers of fathers (2-5) and offspring sample sizes (6-96) using Gerud2.0. Simulations correct = the number of iterations (out of 1000) under the given simulation parameters that produced the correct number of fathers. At sample size $n=32$, the additional data points represents the power to detect a given number of fathers with skew in paternal contribution (one father sired only $1 / 5$ the offspring compared with the other father $(\mathrm{s})$ ). 


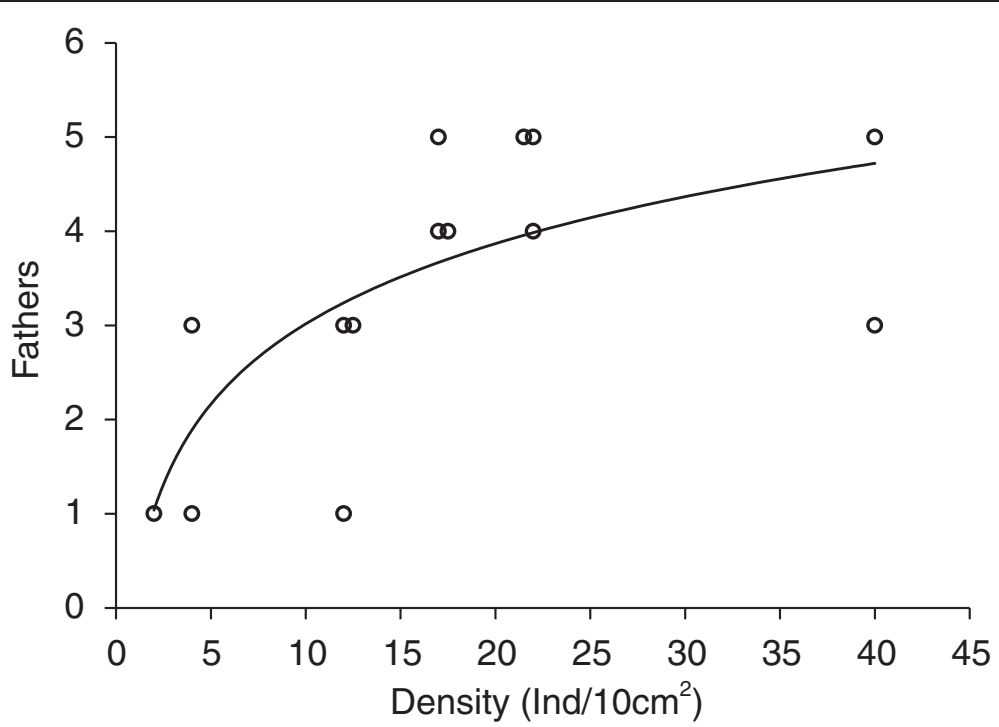

Figure 2 Scatter plot of density versus paternity. Curved line indicates the best-fit logarithmic regression line for the data $\left(r^{2}=0.5122, P=0.004\right)$. Data points are jittered on their $x$-value to show points that had overlapping $x$-y coordinates.

pairwise relatedness between parents was relatively low $($ mean $=0.02)$, though a few parental pairs appeared to show very high relatedness ( $>0.4$; Figure 4$)$.

\section{Genetic analysis of adult barnacles within aggregations}

The eight markers used to examine fine scale population structure and relatedness in the three barnacle aggregations varied in their number of alleles (from four to 12), and showed an overall pattern of high heterozygosity (Additional file 1: Table S1, A1). In aggregation two only, two markers showed significant deviations from Hardy Weinberg equilibrium (Pole 8 and Pole 34; Additional file 1: Table S1). Principal coordinates analysis showed little evidence of allelic differences across the three groups (results not shown). Similarly, overall $F_{\mathrm{ST}}$ was low $(0.007, \mathrm{P}=0.11)$, with only one significant pairwise $F_{\mathrm{ST}}$ comparison (aggregation 1 vs $3: F_{\mathrm{ST}}=0.01, \mathrm{P}=0.003$ ). Relatedness calculations within each group were generally low, (mean $=-0.068)$ with only aggregation one showing a positive average pairwise relatedness (0.008). Relatedness in the first aggregation was significantly greater than expected by chance $(\mathrm{P}=0.013)$ whereas the relatedness estimates for the other two aggregations were not $(\mathrm{P}>0.5)$.

\section{Discussion}

Multiple paternity in P. elegans

Despite modest sample sizes of offspring and relatively low power to detect four and five fathers, we found a

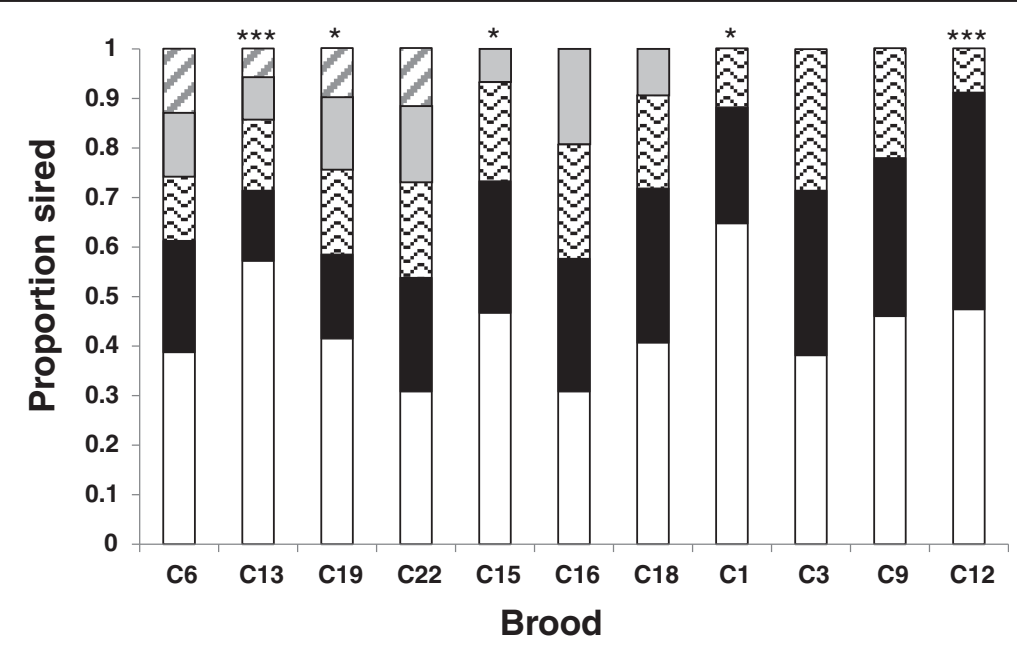

Figure 3 Proportion of brood sired by putative fathers in multiple paternity broods. Asterisks indicate significance of chi-square goodness-of-fit tests for equal reproductive contributions of fathers ( $P<0.05$, ${ }^{* * P}<0.01$, ${ }^{* * *} P<0.001$ ). 


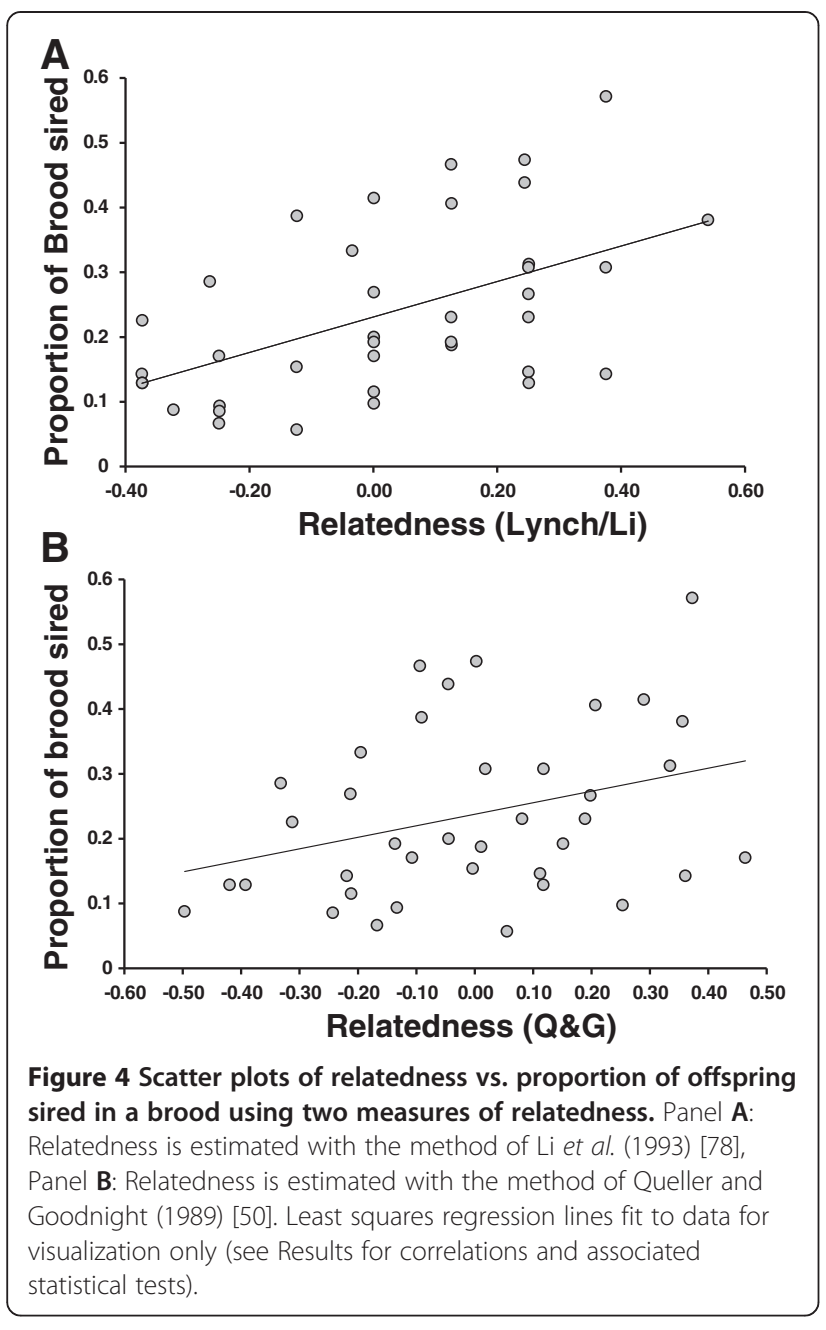

high frequency of polyandry ( $79 \%$ of broods) in P. elegans, with up to five fathers per brood. Both the frequency of polyandry and number fathers in multiply-sired brood P. elegans are greater than what was found in Tetraclita rubescens, an acorn barnacle, which had multiple paternity in $29 \%$ of broods and only $4 / 17$ broods with more than two fathers [47], but are similar to unpublished data for another acorn barnacle, Semibalanus balanoides (D.M. Rand, unpublished, cited in [47]). These contrasting results suggests that the frequency and extent of polyandry varies substantially among barnacle species, as it appears to vary among other copulating crustaceans such as crabs and lobsters (e.g. [51-55]). Similar variation in the frequency of multiple paternity has been observed across species of birds, in which levels of extra-pair paternity vary from $0 \%$ to over $90 \%$ [56].

A significant relationship between barnacle density and the number of fathers contributing to broods suggests that the number of potential sperm donors in an aggregation is a significant factor influencing polyandry in P. elegans. A similar effect of conspecific density on the frequency of polyandry has been shown in other copulating marine $[47,57]$ and terrestrial $[56,58,59]$ species, but not in a spermcasting, brooding colonial ascidian [43]. Unlike spermcasting invertebrates, most barnacles transfer sperm with an extensible penis that can be several times an individual's body length, and the ability to successfully fertilize mates is likely determined largely by the length of the penis and the distance to potential mates $[60,61]$, but see [45]. Total extensible penis length is not known for $P$. elegans, but the recent report of relatively short penis length in a related gooseneck barnacle species [45], suggests that mating may also be limited to close neighbors in P. elegans.

Most broods possessed microsatellite alleles that matched those found in adults sampled from their mother's aggregation, indicating that fertilization occurs primarily by physically proximal males. This result suggests that if spermcasting occurs in P. elegans, it is only effective over short distances, or within aggregations. While we cannot rule out short-distance spermcasting within aggregations (which may be most effective with mates that are close by, especially in the turbulent, high-energy environments that gooseneck barnacles are found), we found no exogenous paternal alleles in any of the low density aggregations and thus no evidence of long-distance spermcasting. Likewise, most individuals in low-density aggregations lacked lamellae entirely, suggesting that longdistance spermcasting is neither common nor effective in P. elegans.

We also observed an apparent upper limit to multiple paternity in $P$. elegans, as indicated by the observation that the linear relationship between the number of fathers siring a brood leveled off at higher densities. Several factors could explain this. First, a lack of power to detect four or more fathers may have produced underestimates of paternity at higher densities resulting in the apparent asymptotic relationship observed between paternity and density. Though power was limited in this study, an upper limit to polyandry may be set by the number of neighbors within reach because penis length is short in Pollicipes, and because spermcasting (to the extent that it occurs in this species) may only be effective over short distances. Lastly, females might actively discard sperm or reject copulations after a certain number of insemination attempts, given that copulations can be costly to survival (at least in some species, [9-13]), potentially limiting the number of contributing males at higher densities. In their meta-analysis of multiple paternity in brooding invertebrate species vs. "pregnant" vertebrates [62], Avise et al. noted the far lower levels of multiple paternity than what is theoretically possible given that brood sizes of marine invertebrate species can be as high as 100,000 embryos. An upper limit to the number of fathers contributing to a brood likely represents a balance 
between the fitness benefits of polyandry and the limitations on multiple mating imposed by logistical or physical factors.

\section{Polyandry and sexual selection in P. elegans}

Evidence of significant skew in paternal contribution and the finding of a significant correlation between genetic similarity and reproductive success suggest that some form of post-copulatory sexual selection may occur in $P$. elegans (though spatial structure in relatedness combined with differential sperm transfer of more proximal neighbors could also produce the observed paternity bias). Paternity bias towards mates with greater genetic similarity could indicate that the specific genetic combination of gametes from the two parents influenced reproductive success, a result that is consistent with a compatible genes model of the benefits polyandry (e.g. $[2,3,18])$. The finding of a positive relationship between genetic similarity and reproductive success contrasts sharply with much of the current literature on the indirect genetic benefits of polyandry, which typically emphasizes a negative relationship between genetic similarity and reproductive success (e.g. [33,34,63-65]). Mating with genetically dissimilar individuals is thought to be beneficial because increased genetic diversity reduces the risk of inbreeding depression, and ensures a range of genotypes for offspring to contend with environmental uncertainty $[2,24]$. Other studies have, however, demonstrated fitness benefits of mating between individuals with a high or intermediate level of genetic similarity $[18,36,37,66]$. Our results show the potential for a similar fitness advantage for fathers that are genetically similar to their mates, supporting the role of compatible genes as a potential benefit of polyandry in this species.

Studies of relatedness in other barnacles may provide clues about why genetically similar mates produce more offspring in multiply-sired broods of $P$. elegans. In the acorn barnacle Semibalanus balanoides, barnacle aggregations from a number of rocky outcrops showed higher average relatedness than expected by chance (as high as 0.14) [48], which is likely driven by oceanography (but larval behavior and kin-aggregation may also play a role) and sets the stage for fine-scale spatial variability in relatedness that may be important during reproduction. Though we found that overall genetic similarity was much lower within adult aggregations of P. elegans (than compared to S. balanoides), our paternity results suggest that during reproduction, there may be a preference for sperm from more genetically similar individuals, even if that similarity is low. Because we could not individually genotype recently-fertilized embryos, it is not clear whether the observed pattern of paternity bias reflects greater fertilization success of compatible gametes or differential post-fertilization viability of compatible embryos. Both scenarios are plausible. Experimental work on the sperm-bindin locus and receptor in various sea urchin species has shown that males with more common or matching bindin genotypes perform better in sperm competition, resulting in greater reproductive success (though this is also mediated by the density of conspecifics and availability of sperm: (e.g. $[35,67])$. Alternatively, a number of studies show that differential embryo survival influences paternity bias, and its inference [68-70]. Future studies of paternity in barnacles should examine paternity bias and differential reproductive success at different time points-post fertilization (brooding embryos) and during the larval stages-to better understand the role of compatibility during fertilization and during the larval stages.

\section{Conclusions}

In summary, we found that multiple paternity is common in the eastern Pacific gooseneck barnacle P. elegans (over $70 \%$ of broods and up to five fathers) and that the number of mates contributing to a brood is associated with the density of conspecifics. We also found that higher relatedness between mates conferred an advantage in male reproductive success within multiply-sired broods, suggesting the potential for cryptic female choice of compatible sperm and that polyandry may confer genetic benefits to brooding individuals, though future studies will be needed to test this explicitly. While density clearly affects the availability of potential mates and thus opportunities for multiple paternity, post-copulatory processes (gamete compatibility or cryptic female choice) may be important in ensuring reproductive success in this sessile, polyandrous species.

\section{Methods}

\section{Sampling and study population}

Barnacles were collected from one 20-m-long rocky outcrop, approximately near Punta Gaspareno, Baja California, Mexico $\left(23^{\circ} 10^{\prime} 58.09^{\prime \prime} \mathrm{N}, 110^{\circ} 8^{\prime} 26.51^{\prime \prime} \mathrm{W}\right)$ in October 2011. Aggregations of barnacles at seven different densities-1, 2, 4, 12, 17, 22, and 44 individuals per $10 \mathrm{~cm}^{2}$ - were sampled haphazardly using a $10 \mathrm{~cm}^{2}$ quadrat (see Table 1). We found few individuals brooding embryos in the lowest density groups; only one of eight groups with a density of two individuals per $10 \mathrm{~cm}^{2}$ and none of the four solitary individuals had embryos. Lower densities ( 1 or 2 individuals) were sampled more than once in an attempt to find individuals that were brooding embryos for paternity analysis. In total, 119 barnacles were sampled, but of these only 21 individuals exhibited brooding embryos, 14 of which yielded larvae for paternity analyses (Table 1; larval culturing description below). Individual barnacles were scraped off of rocks with $1 \mathrm{~mm}$-thick metal paint scrapers and care was taken minimize damage to the bottom of the peduncle 
so that adults were brought back alive. Animals from each aggregation were then placed in individual zip-lock bags and kept moist with rinses of fresh seawater every 68 hours until they arrived at the laboratory $\sim 24$ hours later.

\section{Larval culturing and tissue sampling}

Prior to extraction of the disc-shaped embryo sacs (lamellae), each individual's peduncle was dipped in a $10 \%$ bleach solution, the capitulum was rinsed in $90 \%$ ethanol, and then the whole animal was rinsed thoroughly with 35 ppt artificial seawater (ASW, Instant Ocean). Lamellae (both discs) were extracted from the mantle cavity with forceps, rinsed with ASW, and transferred to clean, $100 \mathrm{ul}$ plastic beakers containing $50 \mathrm{ul}$ of fresh ASW treated with $1 \mathrm{mg} / \mathrm{l}$ each of streptomycin and penicillin to limit bacterial and fungal growth [71]. Larvae from each brood were reared in separate cultures in the dark at $25^{\circ} \mathrm{C}$ [71]; each culture was checked daily for hatching. After hatching, swimming larvae were transferred to new beakers and fed with Rhodomonas salinas and Isochrysis galbana at concentrations of 10,000 cells $\mathrm{ml}^{-1}$ each for $\sim 48 \mathrm{~h}$ until sufficient numbers of stage-II larvae could be collected (50 or more) and preserved in $70 \%$ ethanol. Larvae were fed for $48 \mathrm{~h}$ after hatching because larger larvae yielded more DNA, facilitating individual genotyping. Peduncle tissue of mothers with broods that had 50 or more stage-II larvae were sampled and preserved in ethanol.

DNA was extracted from $\sim 25 \mathrm{mg}$ of adult muscle tissue using a modified CTAB protocol (Doyle and Doyle 1987) with two chloroform/isoamyl isolations and two $70 \% \mathrm{EtOH}$ washes. Precipitated adult DNA was re-suspended with Qiagen EB buffer (10 mM Tris, ph 8.5; Qiagen Valencia CA). DNA from larvae were extracted individually in $200 \mathrm{ul}$ 96-well PCR plates using 25 ul of extraction buffer comprised of $0.5 \%$ tween, TE buffer (10 mm Tris, $1 \mathrm{mM}$ EDTA), and $2.5 \mathrm{ul} 20 \mathrm{mg} / \mathrm{ml}$ Proteinase $\mathrm{k}$ (Bioline). Larval extractions were incubated at $60^{\circ} \mathrm{C}$ for 4 hours followed by 30 minutes at $95^{\circ} \mathrm{C}$ and stored at $-20^{\circ} \mathrm{C}$. Raw (unprecipitated) larval extractions were used directly in PCR.

\section{Genotyping and paternity analysis}

Brooding individuals (mothers) and offspring were genotyped with at least three of five loci: Pole 1, Pole 8, Pole 25, Pole 29, and Pole 44 [72]. These loci have a high number of alleles (5-23) and gene diversity (average expected heterozgosity $=0.59$ ), show no evidence of null alleles, and exclusion probabilities calculated from the four most commonly genotyped markers (Pole 1, Pole 8 , Pole 25, Pole 44) showed high discriminatory power (0.94; genotype data from Gaspareno, Mexico in [72]). PCR was carried out as described in Plough and Marko [72] and fragment analysis was run on the $\mathrm{ABI} 3100$ sequencer at the Arizona State University DNA Lab. Electropherograms were scored by eye using LIZ600 (Applied Biosystems) as an internal size standard on the Peak Scanner software v. 1.0 (Applied Biosystems). Note that because P. elegans is hermaphroditic, all individuals, including brooding mothers are potential fathers.

Paternity analysis was performed using the program GERUD 2.0 [73]. The software does not allow for missing data, so only larvae that successfully amplified at all loci were included in the analysis of each brood. In one brood (c22), two larvae (0.48\% of all genotyped larvae) were each homozygous at a single microsatellite locus for an allele that differed from the mother's, violating assumptions of Mendelian segregation. These larvae were removed from the analysis as possible contaminants from another brood but de-novo mutation at this locus could also explain the observed segregation pattern (e.g. $[74,75])$. Multiple genotype array solutions for the fathers were ranked by likelihood using the default test for Mendelian segregation. Though GERUD2.0 has the option of ranking solutions by allele frequencies from a reference or base population, we were not able to use this feature because some of the broods exhibited rare alleles not present in the genotype data from [72]. To determine if offspring were likely sired by fathers in the same physical aggregations, we examined whether the alleles observed in larval broods were also present in the genotypes of adults from the same aggregations in which those broods were collected. We compared larval and adult genotypes from each of two low density aggregations ( 2 individuals $/ 10 \mathrm{~cm}^{2}$ and 4 individuals $/ 10 \mathrm{~cm}^{2}$ ) and eight broods from three high density aggregations (17, 22, and 44 individuals $/ 10 \mathrm{~cm}^{2}$; Table 1 ). All of the adults within the two low-density groups were genotyped, but in the three higher density aggregations we were able to genotype only $\sim 80-95 \%$ of the adults because some individuals were damaged during collection and/or transport, compromising the quality of the DNA.

\section{Power analysis of paternity}

To determine the power to detect different levels of multiple paternity given the offspring sample size and the number of contributing fathers, we ran simulations using GERUDSIM 2.0. We determined the proportion of simulations out of 1000 that correctly assigned the true number of fathers (from 2-5), given various sample sizes of larvae genotyped (range, two - 96; actual mean sample size across the 14 broods $=29.74$ ) and the population allele frequencies of the four most commonly used markers (Pole 1, Pole 8, Pole 25, and Pole 44) from Baja California, Mexico [72]. Simulations were run assuming that the mothers' genotype was known and that the total offspring number per female (the average number of fertilized eggs) was 5000. In the simulations, five thousand offspring is then split among the true number of fathers for a given 
simulation scenario (e.g. for the 3 father simulation with equal reproductive contribution, each would be assigned 1666 offspring). Fecundity in $P$. elegans has not been measured systematically, but appears to range from a few thousand to 10's of thousands of eggs per female based on observations from this study, and estimates for the related barnacle Pollicipes pollicipes are similar [76]. Simulations with greater than 5000 total offspring ran extremely slowly in GerudSim2.0, but a few trial runs with 25,000 vs 5,000 total offspring yielded similar power results, so we set the total number of offspring in a brood to 5000 . We also determined the power to detect the true number of fathers in a brood when there was skew in paternal contribution: $1 / 5$ the contribution from one father and equal contributions from the others. These simulations were run only at the approximate mean offspring sample size (30). For example, in the case of five fathers, we assigned one father only 200 offspring and the other fathers 1,000 .

\section{Statistical and genetic analyses}

Linear regression analysis of the effect of density on paternity was performed in the $\mathrm{R}$ statistical software package, v. 2.11.1 [77]. To examine skew in the reproductive contribution of putative fathers, Chi-square goodness-of-fit tests were run in R 2.11.1, with the null hypothesis of equal reproductive contribution. We also examined the association between relatedness of mates (calculated from the reconstructed paternal genotypes and the observed genotypes from the mother of each brood) and proportional paternity success. Relatedness was estimated with the Lynch \& Li method [78] in COANCESTRY [79], because it performs well in a number of situations (e.g. [80]). Given the structure of the data (proportions within each brood sum to 1 and are grouped by female) we used a non-parametric, permutation-based approach to assess the significance of the relationship between relatedness and proportional siring success, because it makes fewer assumptions than analysis of variance or linear mixed-model methods. We implemented a permutation-based test of correlation using Spearman's Rho (a non-parametric analog to Pearson's correlation coefficient) that shuffles relatedness values while holding proportion sired static, within each female. The correlation is estimated for the true data, and then calculated after each permutation, and the number of permutations (out of 10,000) in which the permuted value is greater than the actual value is tallied for the onetailed statistical test. This analysis was performed in $\mathrm{R}$ 2.11.1 (see Additional file 2).

Adults from three high density aggregations of barnacles (44, 17 , and 22 individuals per $10 \mathrm{~cm}^{2}$ ) were genotyped to assess relatedness among adults and possible fine-scale population structure. The relatedness estimator of $\mathrm{Li}$ [78] with weighting by locus [81] was calculated in the program STORM [82]. STORM calculates relatedness within a group or population and uses a permutation procedure to shuffle individuals across populations, creating a distribution of expected relatedness values for each group and overall, against which significance can be assessed. We calculated relatedness in the three aggregations, performing 10,000 permutations to determine if barnacles in these aggregations showed greater relatedness than expected by chance. For these calculations, data from eight microsatellite markers were used (Additional file 1: Table S1). Allele counts, heterozygosities, and tests of Hardy Weinberg Equilibrium were calculated with ARLEQUIN v. 3.5 [83]. We also examined fine scale population structure of the three aggregations using principle coordinates analysis (PCoA) and standard F-statistics. PCoA analysis was performed with the GENALEX 6.2 software [84], and pairwise and overall $F_{\text {st }}$ was estimated with GENETIX using 10,000 permutations [85].

\section{Additional files}

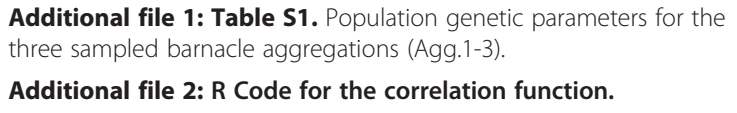

\section{Competing interests}

The authors declare that they have no competing interests.

\section{Authors' contributions}

LVP and PM conceived of the study, and LVP carried out all the molecular work and the data analyses. LVP, PM, and AM wrote the manuscript. All authors read and approved the final manuscript.

\section{Acknowledgements}

The authors thank S. Crickenberger for assistance collecting samples and for help in experimental design. This work was supported by NSF grant OCE-0961996 to P. Marko.

\section{Data accessibility}

Microsatellite genotype data for all samples have been deposited in Dryad: doi: 10.5061/dryad.ct74m.

\section{Author details}

${ }^{1}$ Horn Point Laboratory, University of Maryland Center for Environmental Science, P.O. Box 775, Cambridge, MD 21601, USA. ²Department of Biological Sciences, University of Hawaii at Manoa, 2500 Campus Road, Honolulu HI 96822, USA.

Received: 4 March 2014 Accepted: 31 March 2014 Published: 16 April 2014

\section{References}

1. Andersson M: Sexual Selection. Princeton, NJ: Princeton University Press; 1994.

2. Jennions MD, Petrie M: Why do females mate multiply? A review of the genetic benefits. Biol Rev 2000, 75:21-64.

3. Simmons LW: The evolution of polyandry: sperm competition, sperm selection, and offspring viability. Annu Rev Ecol Evol S 2005, 36:125-146.

4. Trivers RL: Parental Investment and Sexual Selection. In Sexual Selection and the Descent of man 1871-1971. Edited by Campbell B. Chicago, Illinois: Aldine Publishing Co; 1972:136-179.

5. Bateman AJ: Intra-sexual selection in Drosophila. Heredity 1948, 2:349-368. 
6. Rolff J, Siva-Jothy MT: Copulation corrupts immunity: a mechanism for a cost of mating in Insects. P Natl Acad Sci USA 2002, 99:9916-9918.

7. Rowe $L$ : The cost of mating and mate choice in water striders. Anim Behav 1994, 48:1049-1056.

8. Arnqvist G, Nilsson T: The evolution of polyandry: multiple mating and female fitness in insects. Anim Behav 2000, 60:145-164.

9. Reinhardt K, Naylor R, Siva-Jothy MT: Reducing a cost of traumatic insemination: female bedbugs evolve a unique organ. Proc $R$ Soc $B$ 2003, 270:2371-2375

10. Arnqvist G, Rowe L: Sexual Conflict. Princeton: Princeton University Press; 2005.

11. Campbell JF: Fitness consequences of multiple mating on female Sitophilus oryzae L. (Coleoptera: Curculionidae). Environ Entomol 2005, 34:833-843.

12. Den Hollander M, Gwynne DT: Female fitness consequences of male harassment and copulation in seed beetles, Callosobruchus maculatus. Anim Behav 2009, 78:1061-1070.

13. Lange R, Gerlach T, Beninde J, Werminghausen J, Reichel V, Anthes N: Female fitness optimum at intermediate mating rates under traumatic mating. PLOS One 2012, 7:e43234. doi:10.1371/journal.pone.0043234.

14. Birkhead TR, Møller AP: Sperm Competition and Sexual Selection. San Diego: Academic Press; 1998.

15. Eberhard WG: Female Control: Sexual Selection by Cryptic Female Choice. Princeton: Princeton University Press; 1996.

16. Newcomer SD, Zeh JA, Zeh DW: Genetic benefits enhance the reproductice success of polyandrous females. P Natl Acad Sci USA 1999, 1999(96):10236-10241.

17. Eberhard WG: Female Roles in Sperm Competition. In Sperm Competition and Sexual Selection. Edited by Birkhead TR, Moller AP. London: Academic Press; 1998:91-116.

18. Neff BD, Pitcher TE: Genetic quality and sexual selection: an integrated framework for good genes and compatible genes. Mol Ecol 2005, 14:19-38.

19. Puurtinen M, Ketola T, Kotiaho JS: The Good-genes and compatible-genes benefits of mate choice. Am Nat 2009, 174:741-752.

20. Davies NB: Dunnock Behavior and Social Evolution. Oxford UK: Oxford University Press; 1992.

21. Alcock J: Animal Behavior. 7th edition. Sunderland: Sinauer Associates; 2002

22. Slatyer RA, Jennions MD, Backwell PRY: Polyandry occurs because females initially trade sex for protection. Anim Behav 2012, 83:1203-1206.

23. Zeh DW, Smith RL: Paternal investment by terrestrial arthropods. Am Zool 1985, 25:785-805.

24. Yasui $Y$ : The "genetic benefits" of female multiple mating reconsidered. Trends Ecol Evol, 13:246-250.

25. Tregenza T, Wedell N: Polyandrous females avoid costs of inbreeding. Nature 2002, 415:71-73.

26. Fox CW, Rauter CM: Bet-hedging and the evolution of multiple mating. Evol Ecol Res 2003, 5:273-286.

27. Parker GA: Sperm competition and its evolutionary consequences in the insects. Biol Rev 1970, 45:225-267.

28. Keller L, Reeve HK: Why do females mate with multiple males? The sexually selected sperm hypothesis. Adv Stud Behav 1995, 24:291-315.

29. Zeh JA, Zeh DW: The evolution of polyandry. I. Intragenomic conflict and genetic incompatibility. Proc $R$ Soc B 1996, 263:1711-1717.

30. Zeh JA, Zeh DW: The evolution of polyandry II: post-copulatory defense against genetic incompatibilities. Proc $R$ Soc B 1997, 264:69-75.

31. Tregenza T, Wedell N: Benefits of multiple mates in the cricket Gryllus bimaculatus. Evolution 1998, 52:1726-1730.

32. Stockley P: Sperm selection and genetic incompatibility: does relatedness of mates affect male success in sperm competition? Proc $R$ Soc B 1999, 266:1663-1669.

33. Olsson M, Shine R, Madsen T, Gullberg A, Tegelström H: Sperm selection by females. Nature 1996, 383:585.

34. Gasparini C, Pilastro A: Cryptic female preference for genetically unrelated males is mediated by ovarian fluid in the guppy. Proc R Soc B 2011, 278:2495-2501.

35. Palumbi SR: All males are not created equal: Fertility differences depend on gamete recognition polymorphisms in sea urchins. P Natl Acad Sci USA 1999, 96:12632-12637.

36. Peer K, Taborsky M: Outbreeding depression, but no inbreeding depression in haplodiploid ambrosia beetles with regular sibling mating. Evolution 2005, 59:317-323.

37. Sherman $\mathrm{CDH}$, Wapstra $\mathrm{E}$, Uller T, Olsson M: Males with high genetic similarity to females sire more offspring in sperm competition in Peron's tree frog Litoria peronii. Proc R Soc B 2008, 275:971-978.
38. Marshall DJ, Evans PJ: The benefits of polyandry in the free-spawning polychaete Galeolaria caespitosa. J Evol Biol 2005, 18:735-741.

39. Marshall DJ, Evans JP: Context-dependent genetic benefits of polyandry in a marine hermaphrodite. Biol Lett 2007, 3:685-688.

40. Grosberg RK: Limited dispersal and proximity-dependent mating success in the sessile colonial ascidian Botryllus schlosseri. Evolution 1987, 41:372-384.

41. Bishop JD, Pemberton AJ: The third way: spermcast mating in sessile marine invertebrates. Int Comp Biol 2006, 46:398-406. doi: 10.1093/icb/icj037.

42. Bishop JD, Pemberton AJ, Noble LR: Sperm precedence in a novel context: mating in a sessile marine invertebrate with dispersing sperm. Proc $R$ SOC B 2000, 267:1107-1113.

43. Johnson SL, Yund PO: Varation in multiple paternity in natural populations of a free-spawning marine invertebrate. Mol Ecol 2007, 16:3253-3262

44. Evans JP, Garcia-Gonzalez F, Almbro M, Robinson O, Fitzpatrick JL: Assessing the potential for egg chemoattractants to mediate sexual selection in a broadcast spawning marine invertebrate. Proc R Soc B 2012, 279:2855-2861.

45. Barazandeh M, Davis CS, Neufeld CJ, Coltman DW, Palmer AR: Something Darwin didn't know about barnacles: spermcast mating in a common stalked species. Proc R Soc B 2013, 280:20122919.

46. Murata A, Imafuku M, Abe N: Copulation by the barnacle Tetraclita japonica under natural conditions. J Zool 2001, 253:275-280.

47. Kelly MW, Grosberg RK, Sanford E: Love the one you're with: proximity determines paternity success in the barnacle Tetraclita rubescens. Mol Ecol 2012, 20:5088-5097.

48. Veliz D, Duchesne P, Bourget E, Bernatchez L: Genetic evidence for kin aggregation in the acorn barnacle (Semibalanus balanoides). Mol Ecol 2006, 15:4193-4202

49. McLeod L, Marshall DJ: Do genetic diversity effects drive the benefits associated with multiple mating? A test in a marine invertebrate. Plos One 2009, 4:e6347.

50. Queller DC, Goodnight KF: Estimating relatedness using genetic markers Evolution 1989, 43:258-275.

51. Urbani N, Sainte-Marie B, Sévigny J-M, Zadworny D, Kuhnlein U: Sperm competition and paternity assurance during the first breeding period of female snow crab (Chionoecetes opilio) (Brachyura: Majidae). Can J Fish Aquat Sci 1998, 55:1104-1113.

52. Walker D, Porter BA, Avise JC: Genetic parentage assessment in the crayfish Orconectes placidus, a high-fecundity invertebrate with extended maternal brood care. Mol Ecol 2002, 11:2115-2122.

53. Toonen RJ: Genetic evidence of multiple paternity of broods in the intertidal crab Petrolisthes cinctipes. Mar Ecol-Prog Ser 2004, 270:259-263.

54. Gosselin T, Sainte-Marie B, Bernatchez L: Geographic variation of multiple paternity in the American lobster, Homarus americanus. Mol Ecol 2005, 14:1517-1525.

55. Bailie D, Hynes AR, Prodöhl PA: Genetic parentage in the squat lobsters Munida rugosa and M. sarsi (Crustacea, Anomura, Galatheidae). Mar Ecol-Prog Ser 2011, 421:173-182.

56. Petrie $M$, Kempenaers B: Extra-pair paternity in birds: explaining variation between species and populations. Trends Ecol Evol 1998, 13:52-58.

57. Dupont L, Richard J, Paulet YM, Thouzeau G, Viard F: Gregariousness and protandry promote reproductive insurance in the invasive gastropod Crepidula fornicata: evidence from assignment of larval paternity. Mol Ecol 2006, 15:3009-3021.

58. Westneat DF, Sherman PW: Density and extra-pair fertilizations in birds: a comparative analysis. Beha Ecol Sociobiol 1997, 41:205-215.

59. Ishibashi Y, Saitoh T: Effect of local density of males on the occurrence of multi-male mating in gray-sided voles (Myodes rufocanus). J Mammal 2008, 89:388-397.

60. Darwin C: A Monograph of the Subclass Cirripedia with Figures of all Species. In The Lepadidae, or Pedunculated Cirripedes. Volume 2. London: The Ray Society; 1851.

61. Neufeld CJ, Palmer AR: Precisely proportioned: intertidal barnacles alter penis form to suit coastal wave action. Proc R Soc B 2008, 275:1081-1087.

62. Avise JC, Tatarenkov A, Liu J-X: Multiple mating and clutch size in invertebrate brooders versus pregnant vertebrates. P Natl Acad Sci USA 2011, 108:11512-11517.

63. Stockley P, Searle JB, Macdonald DW, Jone CS: Female multiple mating behavior in the common shrew as a strategy to reduce inbreeding. Proc R Soc B 1993, 254:173-179.

64. Bretman A, Trezenga T: Measuring polyandry in wild populations: a case study using promiscuous crickets. Mol Ecol 2005, 14:2169-2179. 
65. Jehle R, Sztatecsny M, Wolf JBW, Whitlock A, Hodl W, Burke T: Genetic dissimilarity predicts paternity in the smooth newt (Lissotriton vulgaris). Biol Lett 2007, 3:526-528.

66. Bos DH, Williams RN, Gopurenko D, Bulut Z, Dewoody JA: Condition-dependent mate choice and a reproductive disadvantage for MHC-divergent male tiger salamanders. Mol Ecol 2009, 18:3307-3315.

67. Levitan DR, Stapper AP: Simultaneous positive and negative frequency dependent selection on sperm bindin, a gamete recognition protein $\mathrm{n}$ the sea urchin. Strongleocentrotus purpuratus. Evolution 2009, 64:785-797.

68. Evans JP, Garcia-Gonzalez F, Marshall DJ: Sources of genetic and phenotypic variance in fertilization rates and larval traits in a sea urchin. Evolution 2007, 61:2832-2838.

69. Garcia-Gonzalez F: Male genetic quality and the inequality between paternity success and fertilization success: Consequences for studies of sperm competition and the evolution of polyandry. Evolution 2008, 62:1653-1665

70. Garcia-Gonzalez F, Simmons LW: Paternal indirect genetic effects on offspring viability and the benefits of polyandry. Curr Biol 2007, 17:32-36

71. Lewis CA: Development of the gooseneck barnacle Pollicipes polymerus (Cirripedia: Lepadomorpha): fertilization through settlement. Mar Biol 1975, 32:141-153.

72. Plough $L V$, Marko PB: Characterization of microsatellites and repeat density in the pacific goosebeck barnackle, Pollicipes elegans, using next generation sequencing. J Hered 2013, DOl:10.1093/jhered/est064.

73. Jones AG: GERUD2.0: a computer program for the reconstruction of parental genotypes from progeny arrays with known or unknown parents. Mol Ecol Notes 2005, 5:708-711.

74. Jones AG, Rosenqvist G, Berglund A, Avise JC: Clustered microsatellite mutations in the pipefish Syngnathus typhle. Genetics 1999, 152:1057-1063.

75. Steinberg EK, Lindner KR, Gallea J, Maxwell A, Meng J, Allendorf FW: Rates and patterns of microsatellite mutations in pink salmon. Mol Biol Evol 2002, 19:1198-1202.

76. Cruz T, Araujo J: Reproductive patterns of Pollicipes pollicipes (Cirripedia: Pedunculata) in the SW coast of Portugal. J Crustacean Biol 1999, 19:260-267.

77. R Development Core Team: R: A Language and Environment for Statistical Computing. Vienna, Austria: R Foundation for Statistical Computing; 2011. URL http://www.R-project.org/. ISBN ISBN 3-900051-07-0.

78. Li CC, Weeks DE, Chakravarti A: Similarity of DNA fingerprints due to chance and relatedness. Hum Heredi 1993, 43:45-52.

79. Wang J: COANCESTRY: a program for simulating, estimating and analyzing relatedness and inbreeding coefficients. Mol Ecol Res 2011, 11:141-145.

80. Van De Casteele T, Galbusera P, Matthysen E: A comparison of microsatellite-based pairwise relatedness estimators. Mol Ecol 2001, 10:1539-1549.

81. Lynch M, Ritland K: Estimation of pairwise relatedness with molecular markers. Genetics 1999, 152:1753-1766.

82. Frasier TR: STORM: software for testing hypotheses of relatedness and mating patterns. Mol Ecol Res 2008, 8:1263-1266.

83. Excoffier L, Lischer HEL: Arlequin suite ver 3.5: A new series of programs to perform population genetics analyses under Linux and Windows. Mol Ecol Res 2010, 10:564-567.

84. Peakall R, Smouse PE: GENALEX 6: genetic analysis in Excel. Population genetic software for teaching and research. Mol Ecol Notes 2006, 6:288-295.

85. Belkhir K, Borsa P, Chikhi L, Raufaste N, Bonhomme F: 1996-2004 GENETIX 4.05, logiciel sous Windows TM pour la génétique des populations. Montpellier (France): Laboratoire Génome, Populations, Interactions, CNRS UMR 5171 Université de Montpellier II; 2004.

doi:10.1186/1471-2148-14-81

Cite this article as: Plough et al:: Density drives polyandry and relatedness influences paternal success in the Pacific gooseneck barnacle, Pollicipes elegans. BMC Evolutionary Biology 2014 14:81.

\section{Submit your next manuscript to BioMed Central and take full advantage of:}

- Convenient online submission

- Thorough peer review

- No space constraints or color figure charges

- Immediate publication on acceptance

- Inclusion in PubMed, CAS, Scopus and Google Scholar

- Research which is freely available for redistribution 